\title{
Removal of metallic foreign bodies embedded in soft tissues by stereotaxic approach
}

\section{Mehmet Fethi Ceylan ${ }^{1 *}$, Savas Guner ${ }^{1}$, Levent Ediz ${ }^{2}$, Seyyid Serif Unsal ${ }^{1}$, Daghan Isik ${ }^{3}$}

1. Orthopedics and Traumatology

2. Physical Medicine and Rehabilitation

3. Plastic and Reconstructive Surgery

Medicine School of Yuzuncu Yil University, Van, Turkey

Key words: Metallic foreign body, plain X-ray, radiation, stereotaxic approach

\begin{abstract}
Background: A trial fibrillation (AF) is the most common cardiac arrhythmia and increases the risk of stroke and death. Patients with hypertensive have an increased risk of developing atrial fibrillation. RDW (Red blood cell distribution width) levels are elevated in cardiovascular disorders including heart failure, stable coronary disease, acute coronary syndrome, slow coronary flow and stroke.

Objective: To investigate the relation between RDW and AF in patients with hypertensive

Method: We retrospectively examined 126 consecutive hypertensive patients (63 hypertensive patients with AF and 63 hypertensive patients without AF matched with age and sex

Results: The mean age of the study population was $71,09 \pm 8,50$ (af group) and 70,97 $\pm 8,24$ (non-af group) years. RDW level was different among patients with atrial fibrillation and without atrial fibrillation. $(15,13 \pm 1,58$ and $14,05 \pm 1,15 \mathrm{p}<001)$. Logistic regression analysis showed that RDW and left atrial dimension were only independently risk factory associated with atrial fibrillation. (Rdw odds ratio:1,846 CI; 1,221-2,793 p<0,05). Roc curve analyses were applied to determine the cut-off point. Cut-off point was at 14,195 and Sensitive, specificity was $\% 71,4, \% 56$ respectively.

Conclusion: RDW levels were higher in hypertensive patients with atrial fibrillation. An increased RDW level in the patient with hypertension may alert physician on developing or presence of atrial fibrillation.
\end{abstract}

Keywords: A trial fibrillation, red blood cell distribution width, hypertension.

African Health Sciences 2014;14(1): 64-71 http://dx.doi.org/10.4314/ahs.v14i1.10

\section{Introduction}

The most frequently seen foreign bodies in the operated cases are piece of metal, wood and glass. ${ }^{1,2,3}$ In order to be able to determine the localization of the foreign body in the tissue, ultrasound (US), magnetic rezonance imaging (MRI), computed tomography (CT), fluoroscopy and plain radiography (X-ray) imaging techniques have been used. ${ }^{3}$ Of these imagining devices, the most common found, the cheapest and the simplest one is the X-ray graphy.

The removal of the metallic foreign bodies in tissue sometimes lasts for hours and due to the use of fluoroscopic equipment, it is also an important

\section{Correspondence author: \\ Mehmet Fethi Ceylan \\ Yuzuncu Yil Universitesi Tip Fakultesi \\ Ortopedi ve Travmatoloji AD, 65400, Van,Turkey. \\ GSM: 05359524440 \\ E-mail: mfethiceylan@hotmail.com}

desadvantage that medical staff is exposed to radiation. ${ }^{4}$ In addition, at the time when the operating room is busy, instead of delaying the patient, removal of the foreign object can be considered under local anesthesia in the intervention room. The use of the stereotaxic method accompanied by plain radiography would facilitate our business in these conditions.

The most effective method used in the determination of the three-dimensional locaization with $\mathrm{X}$-ray of the foreign object in the body is the method of stereotaxy. In this method, while detecting the piece of metal with X-ray, metal objects such as

injection needle are used for marking. In this study, in 30 patients applying to our emergency department with the complaint of sinking of metallic foreign body, the effectiveness of stereotaxic method which was applied has been evaluated.

\section{Material and Method}

In our study, 30 patients who applied to the emergency service of our hospital between 10 May 
2009 and 30 June 2010 with the complaint of sinking of metallic foreign body into their extremities were evaluated prospectively.

Those who had the injuries in the areas of outside the extremity, those who had the foreign body within the joint and those who injured with non-metallic objects were left out of the study.

Of 30 patients whom we enrolled into the study, 16 were male and 14 were female. The age of the patients, the reasons of the injuries, the distance to our hospital from the city that they were dispatched, whether the surgery was done or not previously, the existence of orthopedics specialist at the hospital that they were dispatched from and the reasons for dispatch were questioned. Moreover, while we were removing the metallic foreign body, the skin incision length that we carried out, the duration of surgery and the patients that we failed were evaluated and recorded.
Before begining the process, tetanus prophylaxis of the patients were questioned and to those who were necessary were inoculated. Then, an intravenous cannula was inserted in the forearm of all patients. At the same time just before the operation, single-dose cefazolin intravenous and antibiotic prophylaxis were given. In the emergency service after the preparedness of the skin, the patients whom the foreign object sank their parts were applied the prilocaine $\left(\right.$ citanest $\left.^{\circledR}\right)$ as local anesthesia. Pediatric patients who have the problem of adaptation were made the sedation with midazolam in addition to local anesthesia. The application of tourniquet would be considered for the risk of bleeding during the operation.

In all patients, by looking anteroposterior(AP) $\mathrm{X}$-ray and taking consideration the entrance hole of foreign body the possible place of the needle was determined (Figure 1).

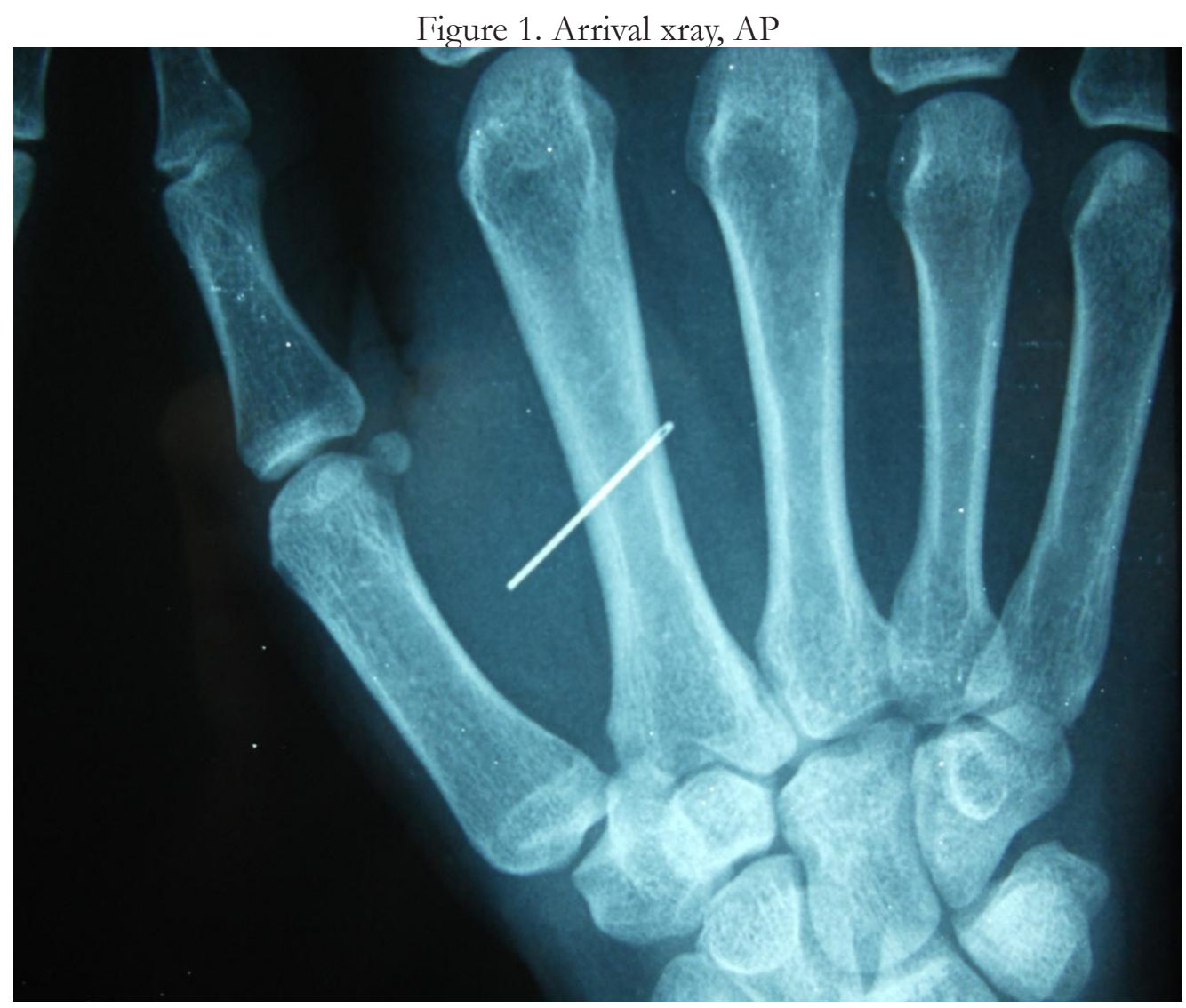


The sign of plus $(+)$ was drawn with the pen of skin so that it would presumably be over the foreign body (Figure 2).

Figure 2. Marking with the pen

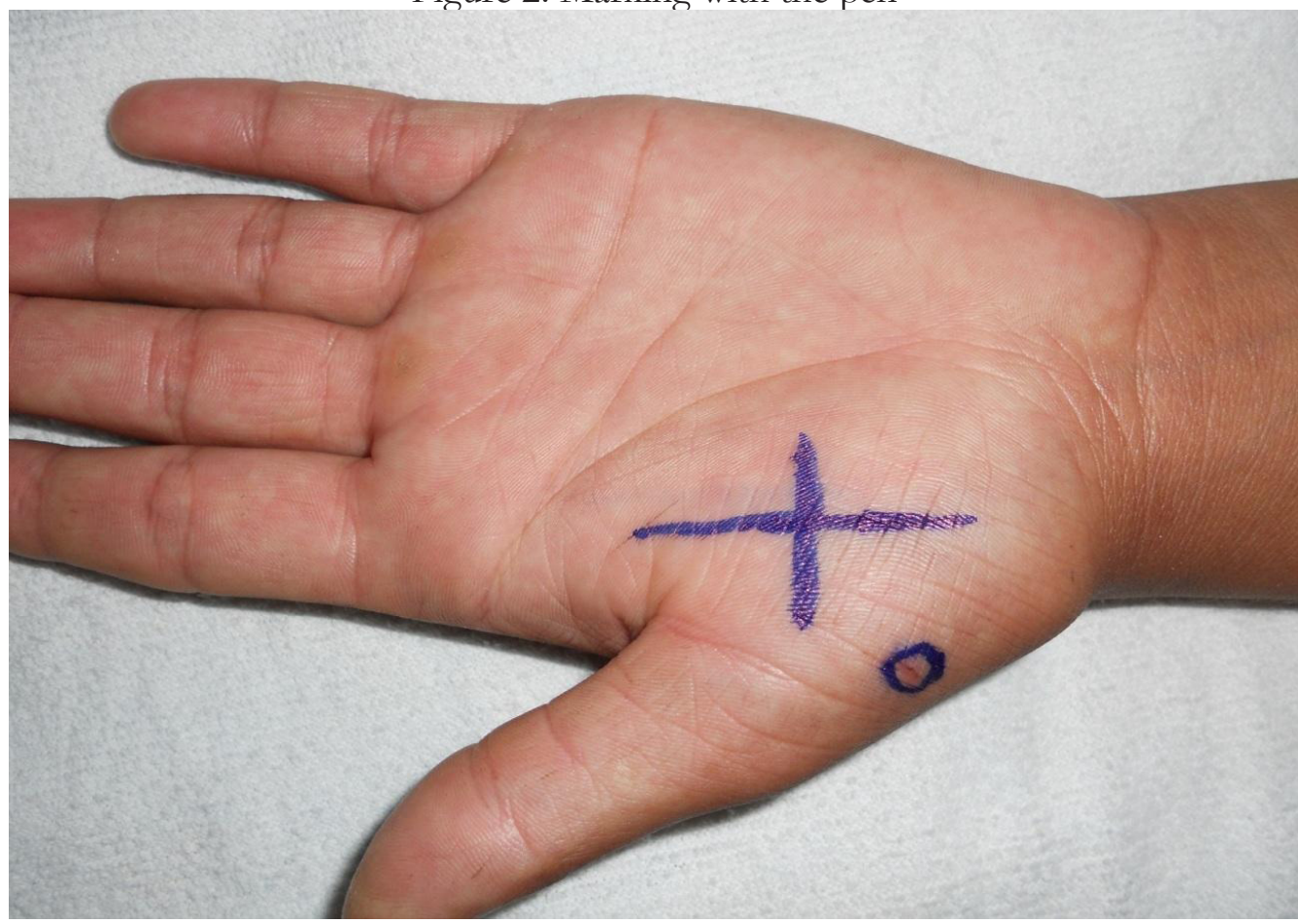

Then two injection needles were fixed by being over the lines and be perpendicular to each other (Figure passed through the skin so that they would come right 3).

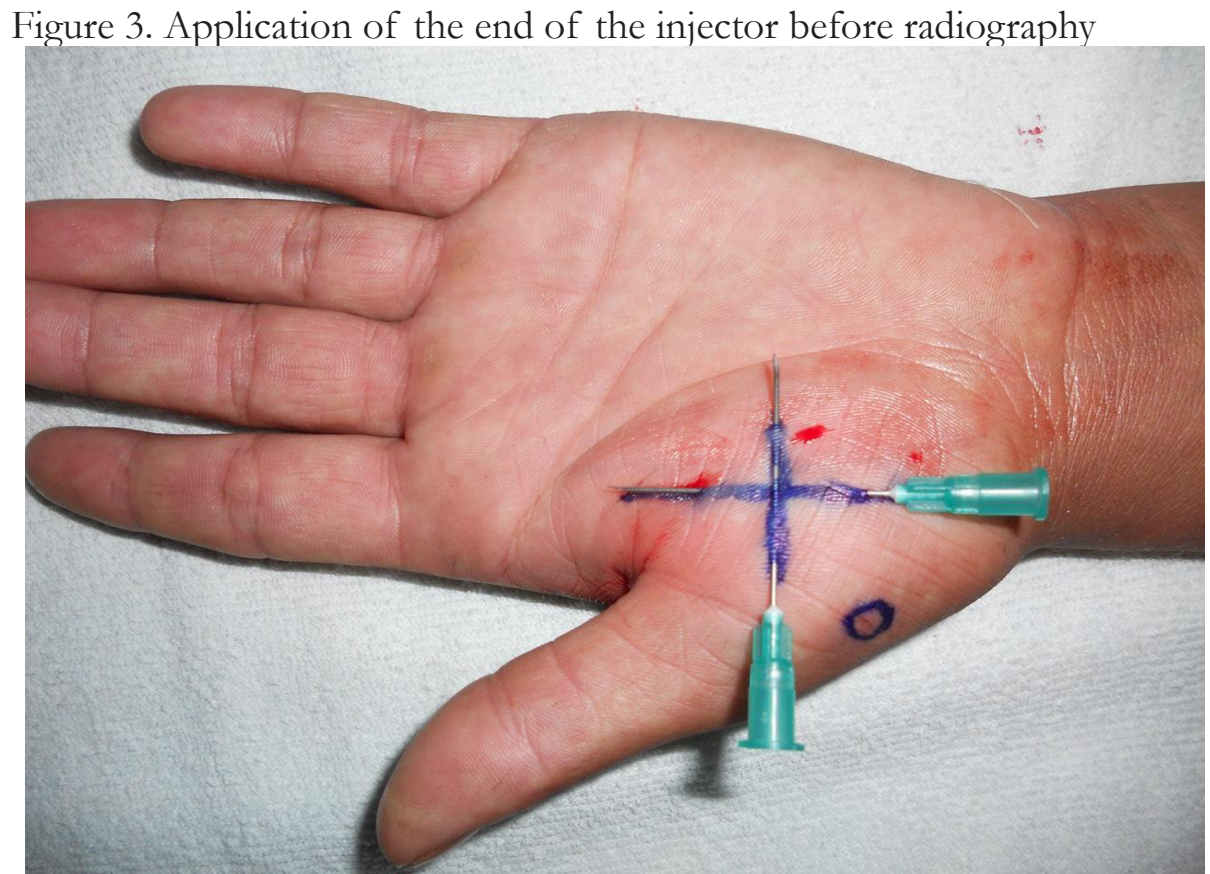

The plain graphies of the area were again taken after the marking according to the needles so that they would be just front-back and just lateral. In all patients, $\mathrm{X}$-ray tube was kept at a distance of one meter to the extremity as a standard and was shot. In AP X-ray, the position of the foreign body was determined according to the needles which were placed (Figure 4). 


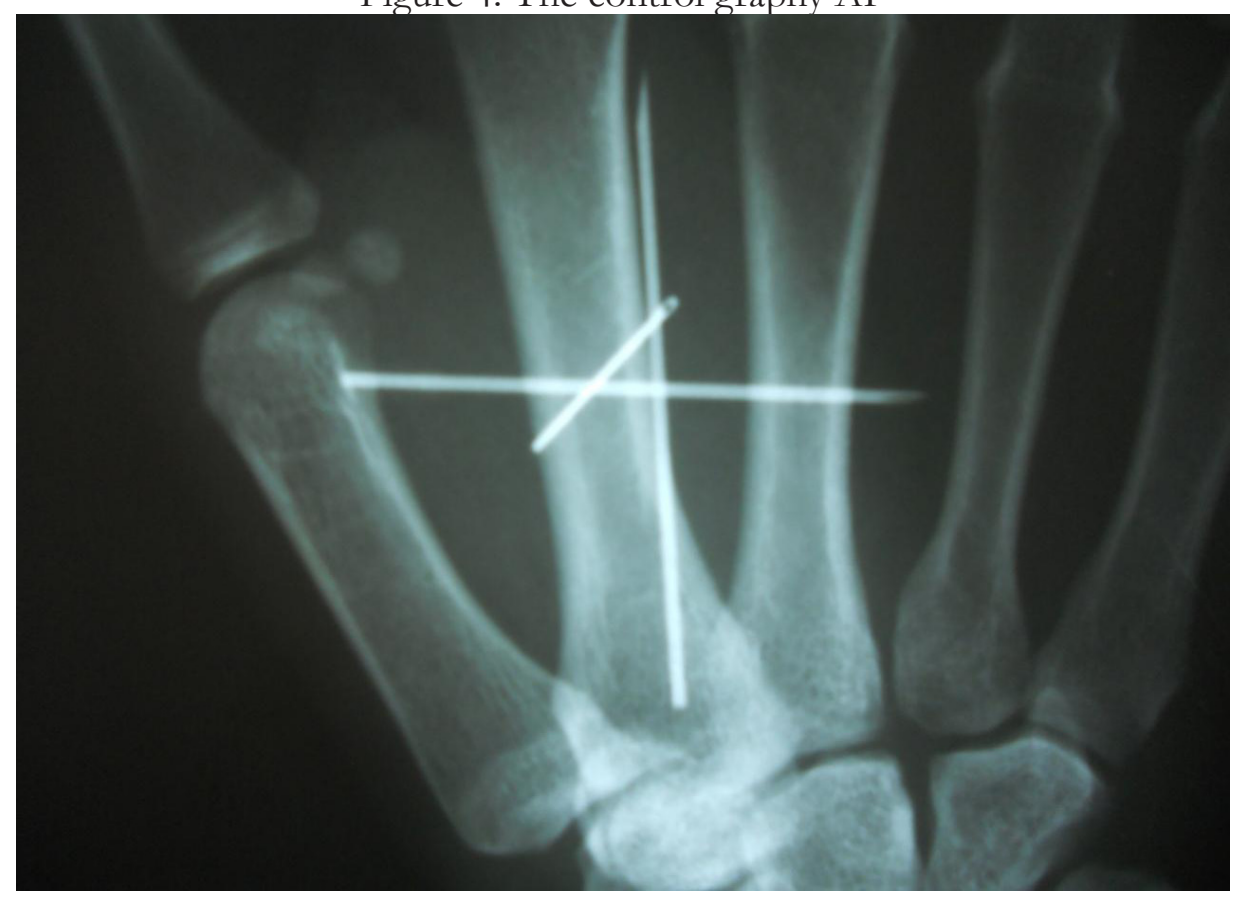

In the lateral graphy, the distance and orientation of the foreign body away from the skin was assessed (Figure 5).

Figure 5. The control graphy lateral $(1.7 \mathrm{~cm}$ away from the skin)

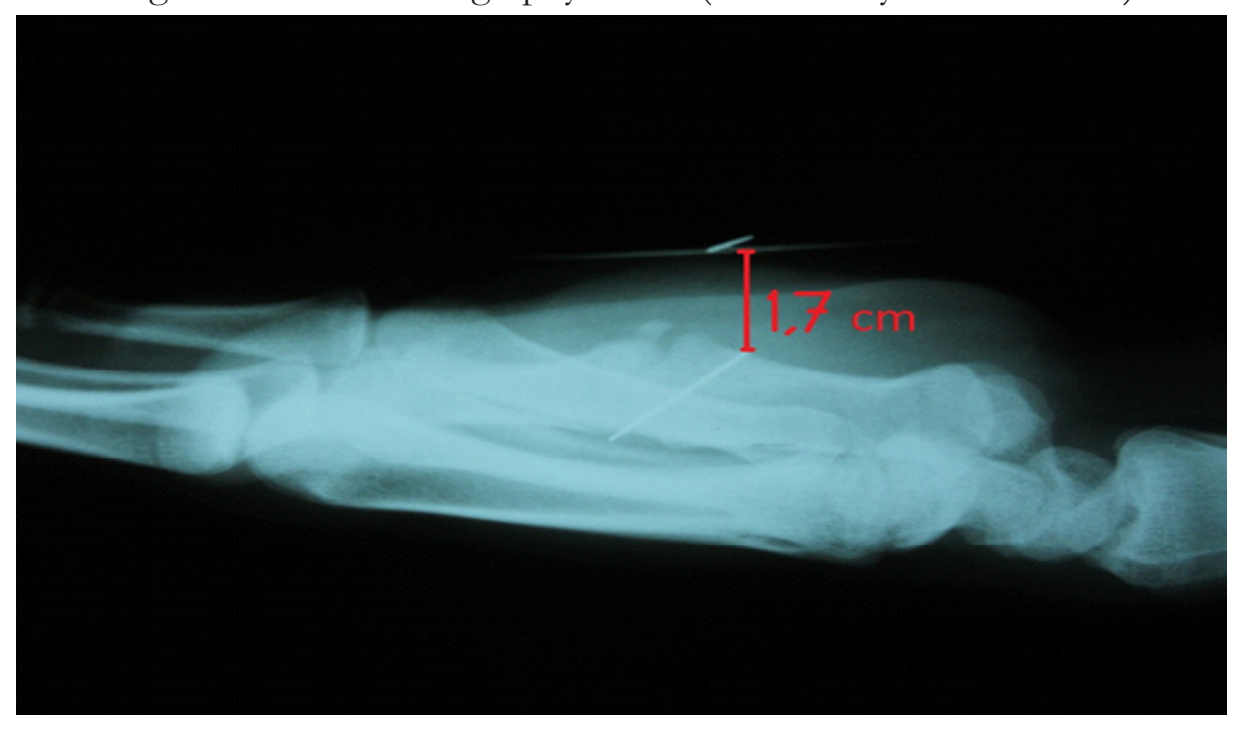

Then the injection tips were removed and under the guidance of marking lines, the skin and subcutaneous incision was made by taking into consideration the distance of the foreign body away from the skin and the lines. In our evaluation on the X-ray, the metallic foreign body was found in the place we determined and was removed (Figure 6). 
Figure 6. The removal of the bodv in the guide of the line

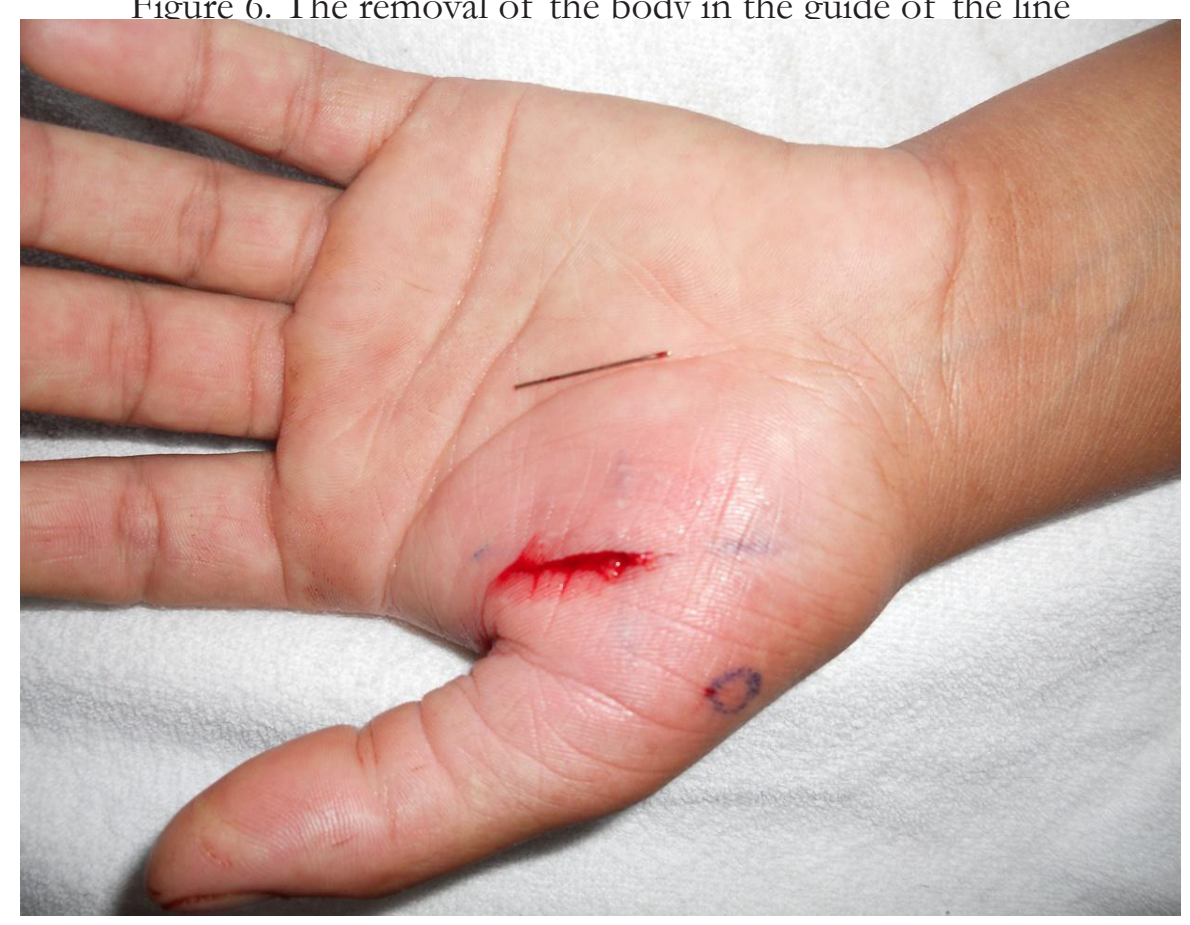

The incisions after the necessary washing and debridement were appropriately sutured.

In the patients who seemed to be necessary after the foreign body was removed, by taking the AP $\mathrm{X}$-ray of the related place the control was made. Then, oral sulbactam-ampicillin and prophylaxis were given to the patients.

All procedures were applied according to the declaration of Helsinki. Signatured consent forms were obtained from all the patients. The study was approved by the ethical committee of the university.

\section{Results}

The cases were between the age of 7 and 64 years. Metallic foreign bodies were in hand and foot in 23 patients $(77 \%)$, in the others were in the other parts of the extremities. 21 of the patients $(70 \%)$ were injured at home with sinking of needle. In the other patients, the foreign body had entered the extremity as a result of the injury with the gunshot and the accident at work. 13 children injured at home as a result of an accident were under the age of 13 (43\%).

At 13 pediatric patients who have the problem of adaptation were made the sedation with midazolam in addition to local anesthesia. During the surgical intervention, significant hemorrhage has not been observed in all patients and so the use of tourniquet has not been required.

A month ago in one of the patients and five months ago in the other the injury had happened with foreign bodies. These patients were refered from the physical therapy clinic that they applied because of the pain of extremity. The other patients had applied to our emergency service at the latest within three days after injury. To the six of the patients $(20 \%)$ had been intervened in another center before our assessment but the foreign body had not been removed. 17 of the patients $(57 \%)$ were referred from the outside of the city. The distances of the arrival of the patients were on average 121 kilometer (15-270). In 19 of the cases $(63 \%)$, it was learned that in the hospitals that they were sent orthopedic specialist was available and in all of these cases, the reason of being referred was that the fluoroscopic device was not found.

In all of the patients the duration of the removal of the foreign body has ranged between 2 and 20 minutes (mean $7.4 \mathrm{~min}$ ). The length of the skin incision's average in the patients was $1.9 \mathrm{~cm}(1-3 \mathrm{~cm})$ (Table 1). 
Table 1. The places of the injury, duration of the operation and the lenght of the cut

\begin{tabular}{|lcccc|}
\hline place & $\mathrm{n}$ & $\%$ & minute & $\mathrm{cm}$ \\
\hline hand & 10 & 33,3 & 7,2 & 1,5 \\
foot & 14 & 46,7 & 8,2 & 2 \\
leg & 2 & 6,7 & 11 & 2 \\
knee & 2 & 6,7 & 4,5 & 2 \\
hip & 1 & 3,3 & 13 & 3 \\
forearm & 1 & 3,3 & 6 & 3 \\
\hline total & 30 & 100 & mean 7,4 & 1,9 \\
\hline
\end{tabular}

When the X-ray of the arrival of eleven patients $(37 \%)$ was evaluated, it was observed that the foreign body was far $3 \mathrm{~cm}$ from the place of the entrance.

In three patients $(10 \%)$ who could not be obtained any compliance under the local anesthesia, the operation was carried out under the general anesthesia in the operating room. The foreign body in all of the patients was removed. In order to determine the location of the foreign body in 2 of the patients, X-ray had to be taken again. In the ankle of one of these patients, for the removal of metallic foreign body being in the posterior of medial malleol skopy was utilized. The average follow-up time of the patients is 10 days (6-14 days). During this period, no complications were encountered.

\section{Discussion}

The substances, found as a foreign object in the body are divided into two as radiopaque and radiolucent. While it is being utilized from the imaging methods such as X-ray, CT and US in the removal of the radiopaque materials, US is often used in those being radiolucent. In 30 patients in this study, it has been aimed that the effectiveness of the removal process of the metallic foreign body from the extremity was prospectively evaluated with the stereotaxic method.

The foreign bodies can be removed successfully with the aid of US. ${ }^{5}$ But while this method is being used, in addition, the specialist of radiology and ultrasound device are needed. Still, the location of the foreign body has been able to be determined with the MRI and $\mathrm{CT}^{6}{ }^{6}$ But the high cost of these devices, the absence of these devices in every hospital and the patient's highdose radiation exposure in CT have limited its uses. In addition, in these methods, too, the localization of the foreign body has been marked but the localizaton has only been determined by the certain anatomical touchstone's (guide) points. In addition, the use of these devices during the removal of the foreign body is not a practical application.

Fluoroscopy has widely been used in the process of removing a foreign body. But, taken by fluoroscopy, radiation's being able to make a carcinogenic effects on the surgical team and the amount of the radiation, which was taken have been determined in the studies. ${ }^{7,8}$ In the method that we applied the surgical team has not exposed to the radiation. In the patients, only at the rate of $93 \%$ the foreign body has been removed by being taken two-sided X-ray. Thus, the patients have been exposed to the doses of radiation much less than fluoroscopy. In addition, the unnecessarily use of the operating room, only because of the fluoroscopy device increases the cost.

In our study, when the arrival X-ray of $11(37 \%)$ patients was evaluated, it was seen that the foreign body was quite in a different place from the location of the entrance. For this reason, to make the process of marking to the region where the object is approximately found according to the arrival X-ray is more accurate. If the marking is done according to the location of the entrance, the object may remain far away from the actual location. This makes it the process of the extraction difficult.

Yildirim and et al, to the whole of the patients 
coming with the injury of the metallic foreign body, their relatives have stated that the injury was in the form of needle sinking at home. ${ }^{9}$ In this study, as a result of the home accident in $83 \%$ of the patients, it was determined that they were injured with a needle-awl. This situation has especially presented that the materials such as needle-awl in homes with children should be kept away from the children.

In the removal of the metallic foreign body, Cincin and et al implemented the method of stereotaxic. But, they, without marking with a pen, have marked just the tip of the injector and have detected the location of the object by taking 3-sided graphy. They have sent away the foreign body without removing the tips of the injector. ${ }^{10}$ While the tips of the injector are being found (present), the operation of the removal of the foreign body may create some of the technical difficulties. This problem has been able to be solved by marking the skin with a skin pencil. In addition, instead of taking 3-sided graphy, it has been determined that taking 2-sided graphy in this study was sufficient.

In more than half of the patients who were dispatched $(63 \%)$ in order to be removed the foreign body, the absence of fluoroscopy device was shown as a justification despite availability of the specialist. However, the plain graphies that we have used in the method of stereotaxic have been present in every health center. Being spread of this method will largely prevent the dispatches. Still, $57 \%$ of our patients have been sent from outside the city and a distance of average $121 \mathrm{~km}$. We believe that the method of stereotaxic that we consider to be successful will prevent the unnecessary dispatch of the patient and the related costs that will be able to arise.

This method that we have applied may not be effective in removing foreign bodies within the locations of the joint, the proximal of the extremity and outside the extremity. Fortunately, the injuries of the foreign body have mostly been in the distal of the extremity. ${ }^{10}$ In $80 \%$ of the cases in this study, the injury had been in the distal of the extremity. The lenght of skin incision and the duration of the operation that we performed during the process are similar to the results of the other two studies that the foreign body was removed with the other method of stereotaxic in the literature. ${ }^{9,10}$ The lenght of the incision and being less of the duration of the process are dependent on being marked and being localized of the foreign body.

In the case which failed with this method, the foreign body was within the deep tissues and tendon. Therefore, the fluoroscopy was needed.

\section{Conclusion}

As a result, even if the assistive devices such as fluoroscopy and ultrasound equipment are absent, most of the foreign bodies may successfully be removed with the aid of the X-ray, found in each hospital and with the method of stereotaxic. With this method, the amount of radiation received during the process of the removal of the foreign body is less than the method of fluoroscopic. But, in being removed of the foreign bodies, found in the deep tissues such as the interval of the joint or inside of the tendon, this method may fail. However, fluoroscopy may be needed in such cases.

\section{References}

1. Peterson JJ, Bancroft LW, Kransdorf MJ. Wooden foreign bodies: Imaging appearance. American Journal of Roentgenology 2002; 178: 557-562

2. Ozsarac M, Demircan A, Sener S, Glass foreign body in soft tissue: Possibility of high morbidity due to delayed migration. J Emerg Med 2009; 20: 30-34

3. Hunter TB, Taljanovic MS. Foreign Bodies. Radiographics 2003; 23: 731-757

4. Müller LP, Suffner J, Wenda K, Mohr W, Rommens PM. Radiation exposure to the hands and the thyroid of the surgeon during intramedullary nailing. Injury 1998; 29( 6): 461- 8

5. Dean AJ, Gronczewski CA, Costantino TG. Technique for emergency medicine bedside ultrasound identification of a radiolucent foreign body. L Emerg Med 2003; 24 (3): 303-308

6. Williamson MR, Espinosa MC, Boutin RD, Orrison WW, Hart BL, Kelsey CA. Metallic foreign bodies in the orbits of patients undergoing MR imaging: Prevalence and value of radiography and CT before MR. American Journal of Roentgenology 1994; 162: 981-983

7. Kirousis G, Delis H, Megas P, Lambiris E, Panayiotakis G. Dosimetry during intramedullary nailing of the tibia. Acta Orthopaedica 2009; 80 (5): 568-572

8. Mroz TE, Yamashita T, Davros WJ, Lieberman IH. Radiation exposure to the surgeon and the patient during kyphoplasty. J Spinal Disord Tech 2008; 21: 96100

9. Yildirim C, Sozuer EM, Avsarogullar1 L, Karaoglu S, Gunay N. Removal of radiopaque foreign bodies ambedded in soft tissues by stereotaxic approach. Turk- 
ish Journal of Trauma and Emergency Surgery 1999; 5 ies embedded within the soft tissues by stereotaxic ap-

(3): $213-216$

proach. The Journal of Medicine of Kartal Training

10. Cincin TG. Removal of radiopaque foreign bod- and Research Hospital 2005; 16 (2): 59 - 62 